\title{
Increased secretion of pro-inflammatory cytokines by circulating polymorphonuclear neutrophils and regulation by interleukin 10 during intestinal inflammation
}

\author{
S Nikolaus, J Bauditz, P Gionchetti, C Witt, H Lochs, S Schreiber
}

Charité University

Hospital, 4th Medical

Humboldt University,

Berlin, Germany

S Nikolaus

J Bauditz

H Lochs

S Schreiber

Clinica Media I, Policlinico S. Orsola, University of Bologna, Italy

P Gionchetti

Charité University Hospital, 1st Medical Department,

Humboldt University, Berlin, Germany

C Witt

Parts of this work have been presented at the 4th

European Gastroenterology Week in Berlin, Germany, 1995.

Correspondence to: Dr S Schreiber, 1st Department of Medicine, Christian-Albrechts-University, Schittenhelmstrasse 12, 24105 Kiel, Germany (email: s.schreiber@mucosa.de).

Accepted for publication 31 October 1997
Department,

\begin{abstract}
Background-Concentrations of proinflammatory cytokines are increased in the intestinal mucosa of patients with active inflammatory bowel disease (IBD). Polymorphonuclear neutrophil granulocytes (PMN) are the most abundant cell type in intestinal lesions in IBD. Interleukin 10 (IL-10) is an important contrainflammatory cytokine which induces downregulation of pro-inflammatory cytokines.

Aims-To investigate whether PMN from patients with IBD or infectious colitis, respectively, secrete increased amounts of pro-inflammatory cytokines and can be regulated by IL-10.

Methods-Secretion (ELISA) as well as corresponding mRNA levels (semiquantitative RT-PCR) of pro-inflammatory cytokines (IL-1 $\beta, T N F-\alpha$ ) and of IL-1 receptor antagonist were assessed in peripheral PMN.

Results-PMN from patients with IBD are primed to secrete enhanced amounts of pro-inflammatory cytokines accompanied by detection of corresponding mRNAs in comparison with normal controls. This finding is not specific for IBD but rather reflects intestinal inflammation in general. IL-10 markedly inhibited proinflammatory cytokine secretion as well as corresponding mRNA concentrations. Conclusions-PMN are an important source of pro-inflammatory cytokines in patients with intestinal inflammation and can be downregulated by IL-10.

(Gut 1998;42:470-476)

Keywords: granulocytes; interleukin $1 \beta$; interleukin 10 ; inflammatory bowel disease; intestinal immunity; inflammation; neutrophils; tumour necrosis factor $\alpha$
\end{abstract}

Table 1 Patient characteristics

\begin{tabular}{lllll}
\hline & Crohn's disease & Ulcerative colitis & Infectious colitis & Normal controls \\
\hline Sex (M/F) & $10 / 21$ & $20 / 18$ & $4 / 5$ & $12 / 12$ \\
Age (range) & $18-41$ & $17-47$ & $18-31$ & $18-48$ \\
Colonic inflammation & All & All & All & None \\
Left sided disease & NA & 14 & NA & NA \\
Pancolitis & 12 & 11 & NA & NA \\
Ileal disease & 27 & 7 & 3 & None \\
Bowel resections & 9 & 1 & None & None \\
5-ASA & 24 & 36 & None & None \\
CDAI/CAI (range) $\dagger$ & $180-340$ & $6-10$ & NA & NA \\
Hospitalised ( $>1$ day) & 11 & 14 & 9 & None \\
\hline
\end{tabular}

^Excluding appendectomy; fonly enrolled patients.
Polymorphonuclear neutrophils (PMN) are the first cells to migrate into tissue sites as part of the host defence system. Their extensive homing into areas of mucosal inflammation led to the development of imaging techniques in which radiolabelled PMN are used for semiquantitative assessment of clinical activity in inflammatory bowel disease (IBD). ${ }^{1-4}$ The homing process is thought to be mediated by specific adhesion molecules expressed on endothelial cells as well as on $\mathrm{PMN}^{5-7}$ The studies by Saverymuttu et al also suggested that neutrophils which have entered the gut wall will transmigrate into the bowel lumen and will then be excreted with stools. ${ }^{3}$ During their migration through the intestinal mucosa PMN are thought to unload a host of mostly non-specific inflammatory mediators including superoxide anions, lipid mediators, and proteases. $^{89}$

Recent studies have demonstrated the ability of peripheral monocytes as well as intestinal macrophages from patients with IBD to secrete enhanced amounts of pro-inflammatory cytokines. ${ }^{10-18}$ Interleukin 1 (IL-1) and tumour necrosis factor $\alpha(\mathrm{TNF}-\alpha)$ may be particularly important for inducing and sustaining intestinal inflammation in IBD..$^{10-13}{ }^{16-19}$ Increased levels of TNF- $\alpha$ have also been reported in the stools of children with active Crohn's disease. ${ }^{20}$ The increased production of pro-inflammatory cytokines in the intestinal mucosa is thought to be a pivotal factor in the pathogenesis of intestinal inflammation in IBD..$^{96-19}$

It has been shown that PMN from patients with active IBD are primed for activation. ${ }^{21-23}$ The earlier reports of a decreased capacity to secrete superoxide anions in vitro may be attributed to the influence of separation techniques $^{24}$ or to the fact that circulating stimulatory substances in the serum samples of these patients have already partially exhausted their capacity for superoxide anion secretion. ${ }^{25}{ }^{26}$ Moreover, it has been demonstrated that elastase, which is a marker enzyme for activated PMN, is increased in the stools and intestinal mucosa of patients with IBD. ${ }^{27}{ }^{28}$

It has been established that normal PMN have the capacity to secrete pro-inflammatory cytokines in vitro ${ }^{29-31}$ which can serve as specific mediators in enhancing immune activation both in a feed back loop to the phagocyte level and by contributing to $\mathrm{T}$ and $\mathrm{B}$ lymphocyte activation. $^{30}$ We therefore investigated the capacity of peripheral PMN of patients with IBD as well as infectious colitis to secrete 
Table 2 Secretion of TNF- $\alpha, I L-1 \beta$ and IL-1ra by PMN from patients with IBD, infectious colitis or normal controls

\begin{tabular}{|c|c|c|c|c|c|c|c|c|}
\hline & \multicolumn{4}{|c|}{ LPS stimulated secretion } & \multicolumn{4}{|c|}{ Spontaneous secretion } \\
\hline & Median & $\begin{array}{l}\text { Lower } \\
\text { quartile }\end{array}$ & $\begin{array}{l}\text { Upper } \\
\text { quartile }\end{array}$ & Number & Median & $\begin{array}{l}\text { Lower } \\
\text { quartile }\end{array}$ & $\begin{array}{l}\text { Upper } \\
\text { quartile }\end{array}$ & Number \\
\hline \multicolumn{9}{|l|}{$\overline{I L-1 \beta(p g / m l)}$} \\
\hline Normal controls & 148 & 90 & 358 & 16 & 20 & 15.8 & 24.5 & 9 \\
\hline Crohn's disease & 595 & 332 & 808 & 22 & 25 & 13.9 & 32.3 & 11 \\
\hline Ulcerative colitis & 487 & 342 & 522 & 16 & 5.3 & 4.9 & 21.0 & 8 \\
\hline Infectious colitis & 445 & 317 & 531 & 9 & 11.1 & 3.0 & 19.2 & 6 \\
\hline \multicolumn{9}{|l|}{$T N F-a(p g / m l)$} \\
\hline Normal controls & 92 & 37 & 164 & 18 & 21 & 11.4 & 26.3 & 9 \\
\hline Crohn's disease & 252 & 162 & 612 & 18 & 25 & 10.2 & 180 & 11 \\
\hline Ulcerative colitis & 264 & 101 & 635 & 14 & 35 & 11.2 & 57.6 & 8 \\
\hline Infectious colitis & 189 & 132 & 632 & 9 & 66 & 8.2 & 132 & 6 \\
\hline \multicolumn{9}{|l|}{ IL-1ra $(p g / m l)$} \\
\hline Normal controls & 2554 & 1243 & 6132 & 15 & 1248 & 1071 & 1693 & 9 \\
\hline Crohn's disease & 8193 & 5670 & 15094 & 16 & 1012 & 734 & 1455 & 11 \\
\hline Ulcerative colitis & 12412 & 9568 & 16311 & 13 & 1030 & 436 & 1560 & 9 \\
\hline Infectious colitis & 3922 & 1440 & 6726 & 8 & 960 & 632 & 1512 & 6 \\
\hline
\end{tabular}

IL-1 $\beta$, TNF- $\alpha$, and IL-1ra. We found an increased capacity to secrete pro-inflammatory cytokines, whereas in vitro secretion of IL-1 ra was not deficient in PMN from patients with bowel inflammation in comparison with normal cells.

The contra-inflammatory cytokine interleukin 10 (IL-10) is a potent mediator for downregulation of monocyte/macrophage activation and for the induction of lymphocyte differentiation. ${ }^{32-37}$ Recent studies indicate that IL-10 can suppress the release of IL- $1 \beta$ and TNF- $\alpha$ by PMN and induces secretion of IL-1ra. ${ }^{33} 3437$ Moreover, IL-10 may be an important novel drug for anti-inflammatory therapy in IBD. ${ }^{37}{ }^{39}$ We found that IL-10 effec-

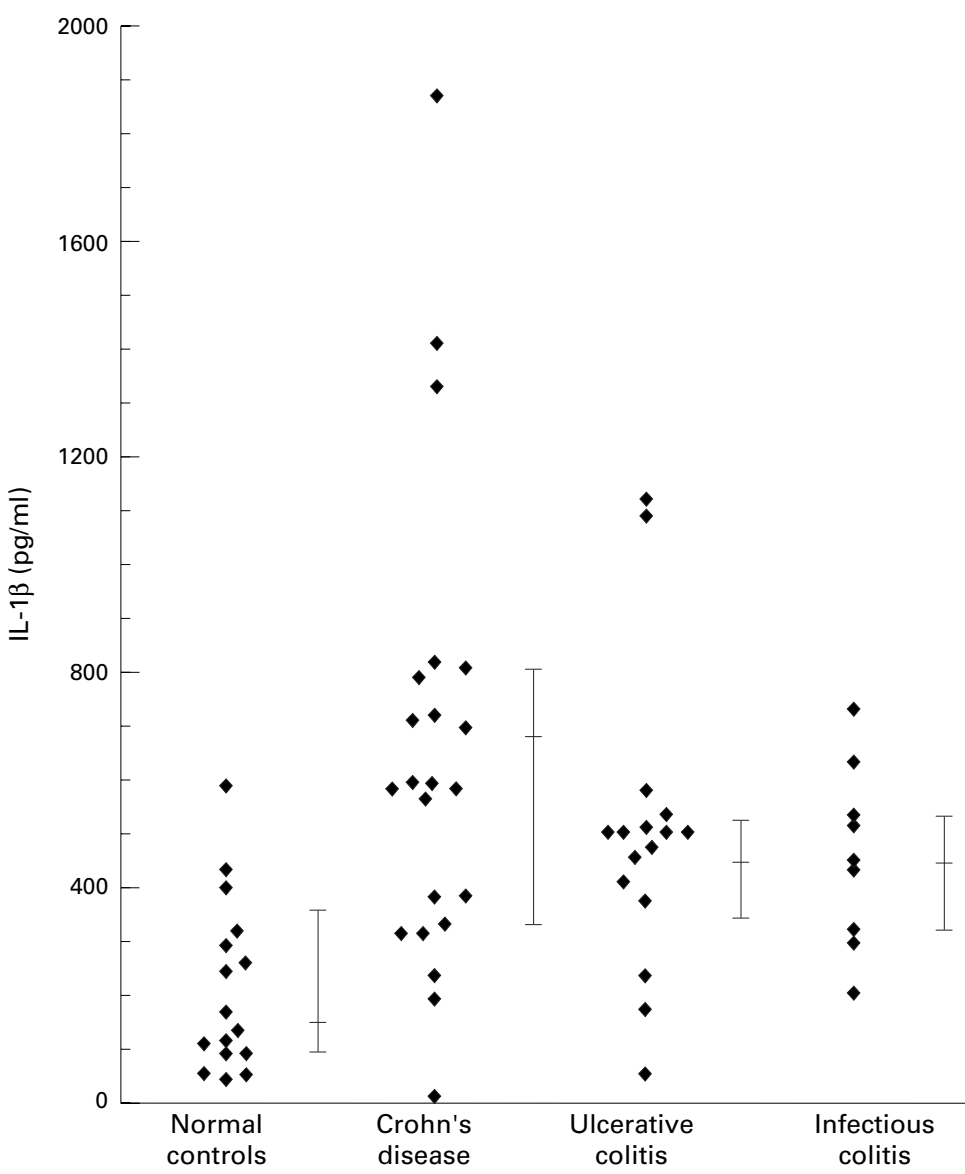

Figure 1 Lipopolysaccharide induced secretion of IL-1 1 by peripheral blood PMN. tively suppresses the release of both IL- $1 \beta$ and TNF- $\alpha$, as well as corresponding cytokine mRNA levels, and induces IL-1 ra secretion by PMN without a difference between IBD and normal control cells in a dose dependent manner.

\section{Methods}

Fetal calf serum (FCS) was purchased from Gibco (Grand Island, New York, USA) or Sigma (St Louis, Missouri, USA). Cytokine enzyme linked immunosorbent assays (ELISA) were obtained from Genzyme/Virotech (Rüsselsheim, Germany) and from DPC Biermann (Bad Nauheim, Germany). Recombinant IL-10 was purchased from Genzyme. All other chemicals were obtained from Sigma if not specified otherwise.

PATIENTS

A total of 31 patients with active Crohn's disease (CD) and 38 patients with active ulcerative colitis (UC) participated in the study between April 1994 and November 1996 (figures show the exact number of patients being investigated in the different experiments conducted). All patients with IBD attended the outpatient clinics of the Charité University Hospital in Berlin because of increased clinical activity. Increased activity was documented both by clinical assessment as well as disease activity indices (table 1). At the time blood was drawn 24 of 31 patients with CD and 36 of 38 patients with UC received treatment with oral salicylates (mesalazine (Salofalk, Claversal, or Pentasa); salazosulfapyridine (Azulfidine or Colopleon); olsalazine (Dipentum)). None of the patients received steroids and/or cytotoxic drugs, immunosuppressive agents or antibiotics at the time of the initial examination. Six patients with active IBD (three CD, three UC) who were started on steroids in a standard dosage (60 mg prednisolone, tapered according to clinical response) were followed longitudinally. All patients with IBD underwent sigmoidoscopy or colonoscopy for routine clinical evaluation and only those with at least moderate activity by endoscopic assessment were included. Patients with ulcerative colitis were required to have at least $20 \mathrm{~cm}$ of inflamed mucosa by endoscopy. Crohn's disease patients were required to show inflammatory lesions in 


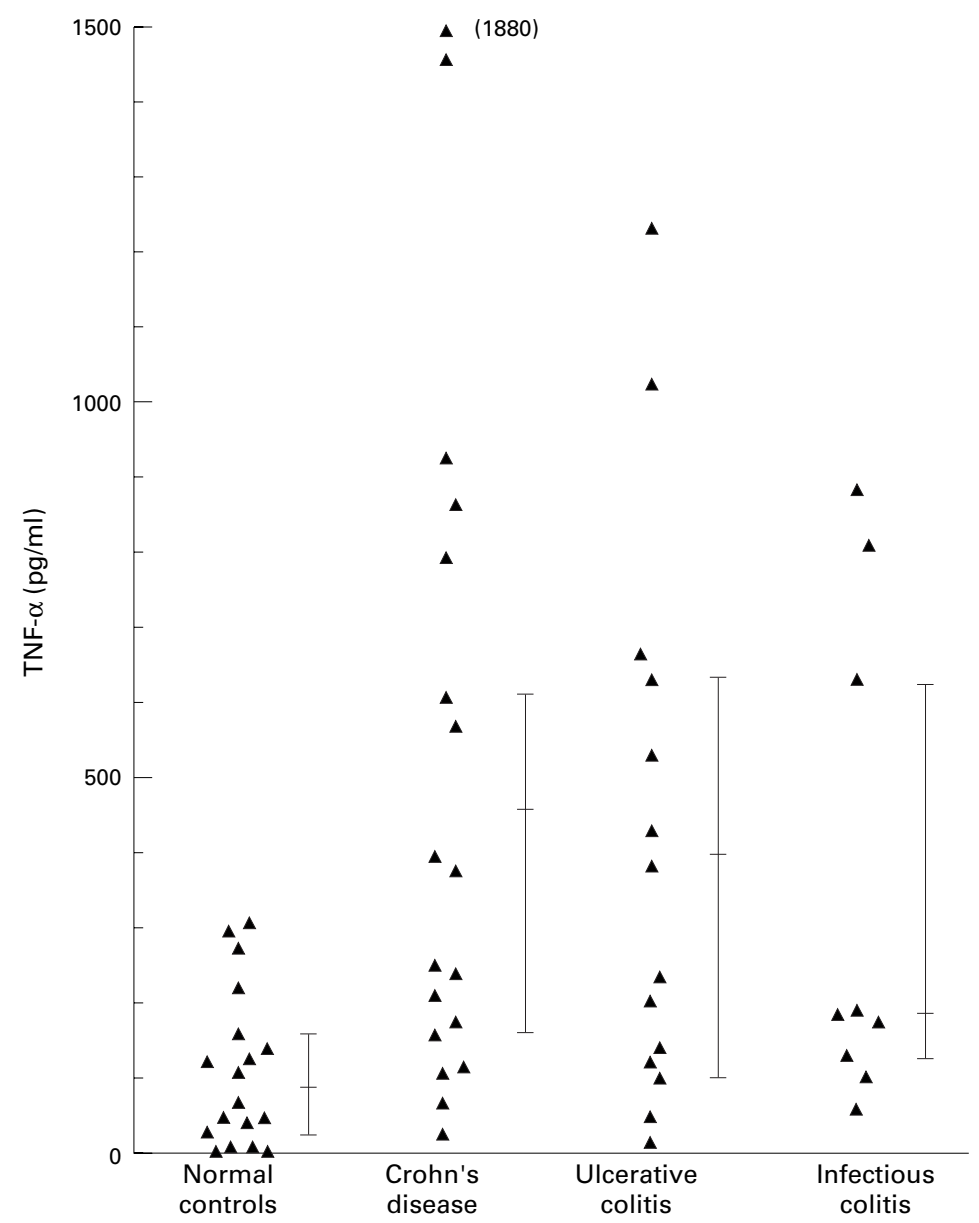

Figure 2 Lipopolysaccharide induced secretion of TNF-a by peripheral blood PMN.

the colon (with and without manifestations in the small bowel) (table 1). Infection or parasites were excluded by stool cultures, microscopic stool examination, and serology.

Patients with IBD kept daily diaries for one week after the examination in which they recorded the occurrence of specific symptoms used to calculate the Crohn's Disease Activity Index (CDAI) or the Clinical Colitis Activity Index (CAI), respectively. ${ }^{41}{ }^{41}$ The CDAI provides a calculated composite score which incorporates eight items: number of liquid or very soft stools, general well being, abdominal pain, abdominal mass, haematocrit, body weight, extraintestinal manifestations, and use of opiate receptor stimulating drugs for the control of diarrhoea. Higher scores indicate more disease activity. Patients with a score below 150 are considered to be in clinical remission and scores above 450 reflect severely active Crohn's disease. The CAI incorporates seven clinical items: number of stools, blood in stools, investigator's global assessment of symptomatic state, body temperature due to colitis, abdominal pain, extraintestinal manifestations, and erythrocyte sedimentation rate. Patients with a CAI of 4 or less are considered to be in remission. Two patients with $\mathrm{CD}$ and one patient with UC did not have active disease with regard to the clinical score and results were excluded from the study analysis.
Blood was drawn after informed consent and the study was granted prior approval by the institutional review board. Normal controls $(\mathrm{NC}, \mathrm{n}=24)$ were age and sex matched healthy volunteers. Patients with bacterial infectious colitis (IC, $n=9$ ) who were admitted to hospital because of severe symptoms and who showed mucosal inflammation by sigmoidoscopic assessment were used as an additional control group (table 1).

HUMAN POLYMORPHONUCLEAR NEUTROPHILS Human PMN were separated from blood as previously described. ${ }^{42}{ }^{43}$ In short, peripheral blood containing $1000 \mathrm{U}$ heparin $/ 10 \mathrm{ml}$ was diluted 1:2 with dextran (Pharmacia, Freiburg, Germany, 3\% in $0.85 \%$ sodium chloride solution). After sedimentation of cells, PMN were pelleted $(400 \mathrm{~g} \times 5 \mathrm{~min})$ and the remaining erythrocytes twice lysed in $0.2 \%$ sodium chloride solution. After 20 seconds the sodium chloride concentration was increased to $0.9 \%$ by isovolumetric addition of $1.6 \%$ sodium chloride. Cells were then pelleted $(400 \mathrm{~g} \times 5$ min) and layered over Lymphoprep (Nycomed, Oslo, Norway) (SG = 1.077) and were centrifuged for 30 minutes at $500 \mathrm{~g}$. Cells from the interphase were discarded and the PMN pellet resuspended and washed in phosphate buffered saline. Viability was more than $98 \%$ (trypan blue) and the cell suspension contained more than 97\% granulocytes (as assessed by morphology in Pappenheim's stain). Monocyte contamination was excluded by double staining for esterases ( $\alpha$-naphthylacetate esterase and chloracetate esterase) and by the random assessment of cell preparations by electron microscopy. ${ }^{4}$ Moreover, human monocytes secrete interleukin-10 when stimulated with lipopolysaccharide which was not found in PMN culture supernatants.

PMN CULTURES AND CYTOKINE ASSAYS

PMN were cultured at a concentration of $1 \times$ $10^{6}$ cells $/ \mathrm{ml}$ in RPMI 1640 (supplemented with $10 \% \mathrm{FCS}, 1 \%$ pyruvate, $100 \mathrm{U} / \mathrm{ml}$ penicillin and $50 \mu \mathrm{g} / \mathrm{ml}$ gentamicin). Cells were cultured in 24 well plates (Nunc, Roskilde, Denmark) with or without lipopolysaccharide $(10 \mu \mathrm{g} / \mathrm{ml})$ in the presence of different concentrations of IL-10 (if applicable). After 24 hours supernatants were separated from cells by centrifugation, snap frozen and stored at $-70^{\circ} \mathrm{C}$ until determination of cytokine levels.

Supernatant concentrations of $\mathrm{TNF}-\alpha$, IL-1 $\beta$ and IL-1 ra were assessed using a specific sandwich enzyme linked immunosorbent assay (ELISA). All samples were analysed in duplicate or triplicate. The amount of cross reactivity was assessed by comparison with the concentration yielding a $50 \%$ inhibition of binding. Specificity of the ELISAs was demonstrated by the finding that up to $100 \mathrm{pg} / \mathrm{ml}$ of IL-1, IL-2, IL-3, IL-4, IL-5, IL-6, IL-8, IL-10, IL-12, G-CSF, GM-CSF and TNF- $\alpha$ showed no significant cross reactivity or interference. Sensitivity levels were between $2.0 \mathrm{pg} / \mathrm{ml}$ (IL$1 \beta)$ and $4.0 \mathrm{pg} / \mathrm{ml}(\mathrm{TNF}-\alpha)$, intra- and inter-assay precision variability was below $3 \% .{ }^{45}$ Repeated thawing and freezing of the 


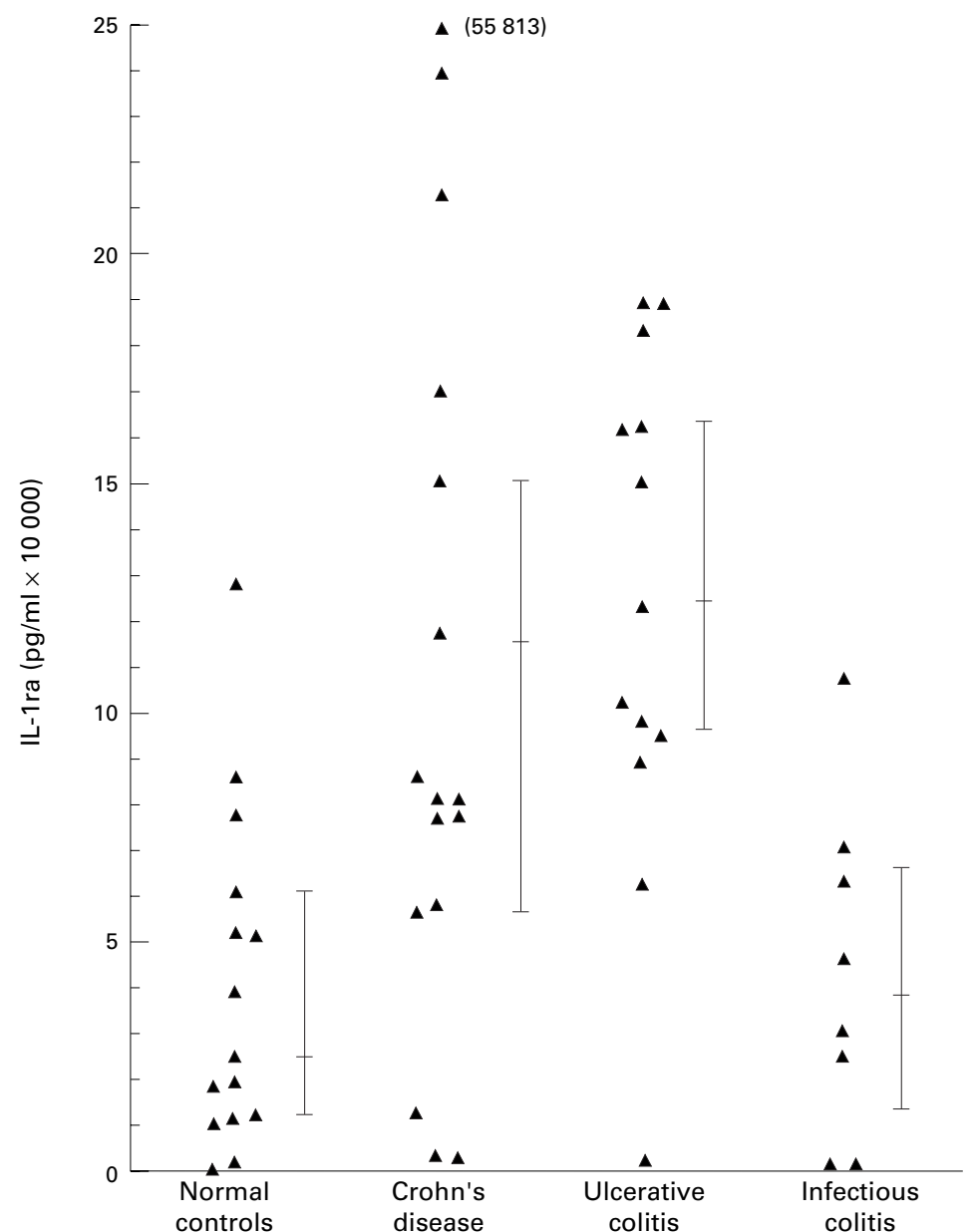

Figure 3 Lipopolysaccharide induced secretion of IL-1ra by peripheral blood PMN.

cultured cells, which would release cytokines stored in the cytoplasm, did not increase the cytokine levels significantly. Therefore all cytokines synthesised were secreted into the supernatants.

REVERSE TRANSCRIPTION POLYMERASE CHAIN REACTION (RT-PCR)

RNA was extracted by a modified guanidiumthiocyanate-phenol-chloroform extraction. ${ }^{46}$ In short, after removal of culture supernatants and washing, cells were lysed in guanidium solution (4 M guanidium-isothiocyanate, $25 \mathrm{mM}$ sodium citrate, $0.5 \%$ sarcosyl, $0.1 \mathrm{M}$ 2-mercaptoethanol, $\mathrm{pH}$ 7.0). After removal of cellular DNA 0.1 volumes of $2 \mathrm{M}$ sodium acetate $(\mathrm{pH} 4.0)$ and one volume of $\mathrm{H}_{2} \mathrm{O}$ saturated phenol as well as 0.2 volumes of chloroform:isoamyl alcohol (49:1) were added sequentially. The mixture was incubated on ice (15 minutes) and then centrifuged (20 minutes $\times 12000 \mathrm{~g}$ ). The watery phase contained RNA which was precipitated overnight with one volume of 2-propanol $\left(-20^{\circ} \mathrm{C}\right)$. After centrifugation $(20$ minutes $\times 12000 \mathrm{~g}$ ) the pellet was again dissolved in $300 \mu \mathrm{l}$ guanidium solution (composed as described above) and precipitated with 2.5 volumes of $100 \%$ ethanol. Following centrifugation the pellet was washed with $70 \%$ ethanol and RNA was resuspended

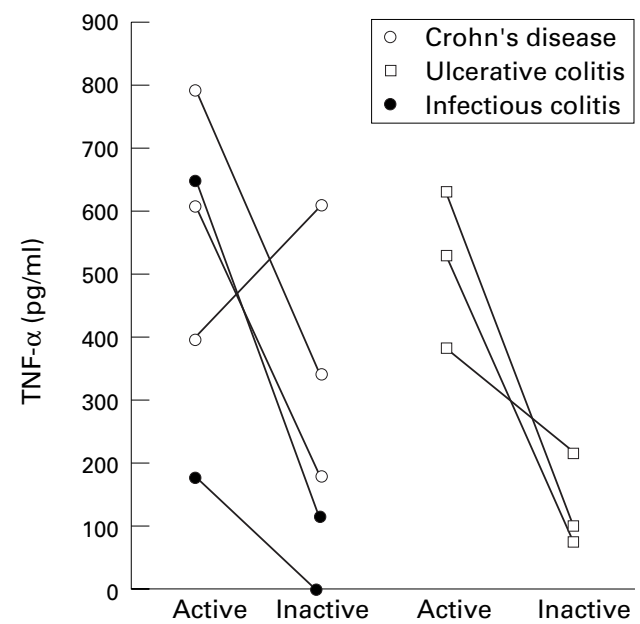

Figure 4 Longitudinal follow up of patients with mucosal inflammation.

in sterile water which had been treated with $0.1 \%$ diethyl pyrocarbonate.

For semiquantitative RT-PCR a cRNA standard (Perkin-Elmer Cetus) was used which contained numerous primer binding sites including those for TNF- $\alpha$ and IL-1 $\beta$. The weight of approximately $300 \mathrm{bp}$ allows easy discrimination between standard and sample derived DNA. Cellular RNA, prepared as described above, containing wild type (authentic) cytokine mRNA was mixed at constant concentrations with a series of samples containing increasing concentrations of synthetic cRNA standard. Aliquots of RNA mixture were reverse transcribed and amplified according to the method described by Wang et al. ${ }^{47}$ Preliminary experiments were carried out to ensure that equimolar concentrations of authentic and synthetic cytokine RNA are amplified with identical efficiency. ${ }^{37}$ These studies of amplification kinetics were repeated at different concentrations and for each cytokine. It was decided to use 25 cycles for amplification of both cytokines because linear amplification and equal amplification efficiency could be achieved over the relevant concentration range from 24-27 cycles (TNF- $\alpha$ ) and 23-27 cycles (IL-1 $\beta$ ), respectively. ${ }^{37}$ The following primer pairs (Perkin Elmer Cetus) were used:

TNF- $\alpha$ : 5'-CAGAGGGAAGAGTTCCCC AG-3' and 5'-CCTTGGTCTGGTAGGAG ACG-3'; IL-1 $\beta$ : 5'-AAACAGATGAAGTGCT CCTTCCAGG-3' and 5'-TGGAGAACACC ACTTGTTGCTCCA-3'.

At the 5 ' end the upstream primer was coupled to a fluorescein molecule. The PCR product was diluted in formamide (with $50 \mathrm{mM}$ EDTA, 1:3) and analysed by denaturing 6\% polyacrylamide gel electrophoresis.

EXPRESSION OF DATA

The symbol $n$ refers to the number of experiments. All experiments were carried out three or more times. Normal distribution of data was evaluated by calculating Lilliefors' probabilities based on the KolmogorovSmirnov test. ${ }^{48}{ }^{49}$ Results are expressed as mean (SE) if distributed normally. Statistical significance of the differences for non-normally 
Table 3 Regulation of TNF- $a$, IL-1 $\beta$ and IL-1ra secretion by IL-10 in PMN from patients with IBD and normal controls

\begin{tabular}{|c|c|c|c|c|c|c|c|c|c|}
\hline \multirow[b]{2}{*}{$I L-10(\mathrm{U} / \mathrm{ml})$} & \multicolumn{3}{|l|}{$T N F-a$} & \multicolumn{3}{|l|}{$I L-1 \beta$} & \multicolumn{3}{|l|}{$I L-1 r a$} \\
\hline & 0 & 10 & 100 & 0 & 10 & 100 & 0 & 10 & 100 \\
\hline \multirow[t]{2}{*}{$\begin{array}{l}\text { Normal controls } \\
\quad(n=7-10)\end{array}$} & 112 & $92 \ddagger$ & $27^{\star}$ & 251 & $122^{\star}$ & $20 \dagger$ & 1272 & $1672^{\star}$ & $1888^{\star}$ \\
\hline & $16-222$ & $27-135$ & $12-32$ & $56-320$ & $54-132$ & $12-32$ & $1221-2039$ & $1514-2412$ & $1712-2378$ \\
\hline \multirow[t]{2}{*}{$\begin{array}{l}\text { Crohn's disease } \\
\quad(n=8-11)\end{array}$} & 252 & $135^{\star \star}$ & $26^{\star \star}$ & 598 & $312^{\star \star}$ & $32^{\star \star}$ & 1085 & $1732^{\star}$ & $2079^{\star \star}$ \\
\hline & $119-795$ & $24-332$ & $25-34$ & $583-720$ & $273-332$ & $18-72$ & $612-1481$ & $1532-2667$ & $1808-2782$ \\
\hline \multirow{2}{*}{$\begin{array}{l}\text { Ulcerative colitis } \\
\quad(n=7-11)\end{array}$} & 212 & $131^{\star}$ & $36^{\star \star}$ & 474 & $272^{\star \star}$ & $51^{\star \star}$ & 1151 & $1773^{\star}$ & $2032^{\star}$ \\
\hline & $143-385$ & $108-147$ & $22-45$ & $372-582$ & $178-278$ & $32-52$ & 979-1988 & $1562-2732$ & $1712-2345$ \\
\hline
\end{tabular}

Values are expressed as median (interquartile range) because the data did not follow a normal distribution. PMN were stimulated with LPS ( $10 \mu \mathrm{g} / \mathrm{ml}$ ) to assess TNF- $\alpha$ and IL-1 $\beta$ release. IL-1 ra release was assessed in non-stimulated PMN. Regulation of cytokine secretion by IL-10 reached statistical significance in each group (Wilcoxon matched pairs analysis versus untreated control cells: ${ }^{\star} \mathrm{p} \leqslant 0.05,{ }^{\star \star} \mathrm{p} \leqslant 0.01,+\mathrm{p} \leqslant 0.005, \neq$ not significant) whereas no statistical differences in the relative capacity of regulation were seen between PMN from normal controls and patients with Crohn's disease or ulcerative colitis.

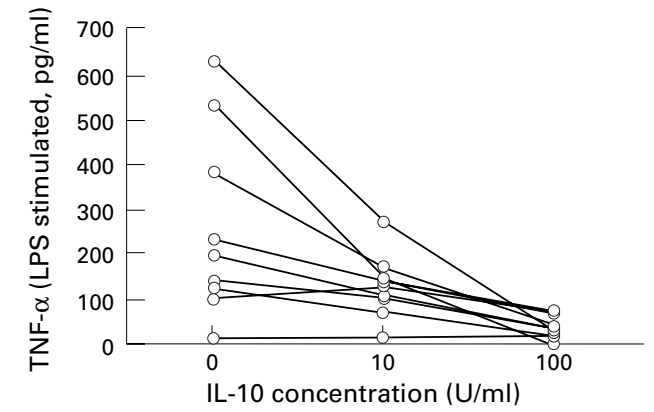

Figure 5 Downregulation of PMN pro-inflammatory cytokine secretion by $I L-10$.

distributed data was tested with the MannWhitney U test or the Wilcoxon matched pairs test, respectively, ${ }^{49}{ }^{50}$ and results are given as mean with interquartile percentiles. ${ }^{50}$

\section{Results}

INCREASED SECRETION OF INTERLEUKIN $1 \beta$ AND TNF- $\alpha$ BY PMN FROM PATIENTS WITH INTESTINAL INFLAMMATION

Spontaneous secretion of IL- $1 \beta$ and TNF- $\alpha$ by PMN was seen only at low levels (table 2). Lipopolysaccharide stimulated secretion of IL-1 $\beta$ (fig 1, table 2) from PMN from patients with Crohn's disease $(p=0.0024)$ and ulcerative colitis $(p=0.0025)$ was higher than that from normal control cells. PMN from patients with infectious colitis also showed increased secretion of IL-1 $\beta$ into culture supernatants in comparison with normal controls $(\mathrm{p}=0.015)$. In a similar fashion secretion of $\mathrm{TNF}-\alpha$ (fig 2 , table 2) into culture supernatants was increased by PMN from patients with Crohn's disease $(\mathrm{p}=0.0026)$, ulcerative colitis $(\mathrm{p}=$ $0.0093)$, and infectious colitis $(p=0.027)$ in comparison with normal controls. Time course experiments demonstrated that more than $70 \%$ of the IL- $1 \beta$ and the TNF- $\alpha$ was secreted during the first eight hours of culture and that after 24 hours maximum concentrations had been reached (data not shown).

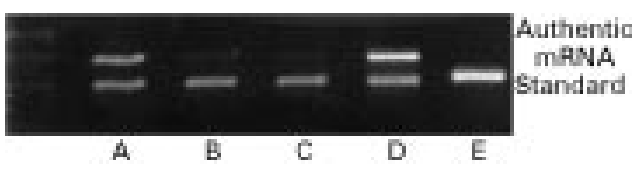

Figure 6 Pro-inflammatory cytokine $m R N A$ in PMN and regulation by $I L-10$.
SECRETION OF IL-1RA IN IBD AND NORMAL PMN Polymorphonuclear neutrophils from patients with IBD and normal controls spontaneously secreted considerable amounts of IL-1ra. Stimulation with lipopolysaccharide greatly increased IL-1ra secretion, with both Crohn's disease $(p=0.019)$ and ulcerative colitis PMN $(\mathrm{p}=0.004)$ producing more than normal controls (fig 3, table 2). Secretion of IL-1 ra did not differ between PMN from patients with infectious colitis and normal controls. No statistical differences in IL- $1 \beta / \mathrm{IL}-1 \mathrm{ra}$ molar ratios were seen between IBD and normal control PMN (data not shown).

SECRETION OF PRO-INFLAMMATORY CYTOKINES BY PERIPHERAL PMN DURING LONGITUDINAL FOLLOW UP

Six patients with IBD were followed into steroid induced remission. All but one patient showed a substantial decrease in the secretion of TNF- $\alpha$ (fig 4) and IL-1 $\beta$ (data not shown). This patient suffered from Crohn's disease. Although in clinical remission at the time of examination, he presented two weeks later with signs of high disease activity. Two patients with infectious colitis were re-examined after complete resolution of symptoms. TNF- $\alpha$ and IL-1 $\beta$ secretion levels declined well into the normal range (fig 4 ).

DOWNREGULATION OF PMN PRO-INFLAMMATORY CYTOKINE SECRETION BY IL-10

Interleukin 10 is a potent contra-inflammatory mediator which downregulated proinflammatory cytokine secretion by PMN from both normal controls and patients with IBD in a dose dependent manner (table 3, fig 5). No differences between IBD and normal control cells were seen with regard to the inhibitory capacity of IL-10. IL-10 downregulation of lipopolysaccharide induced TNF- $\alpha$ and IL-1 $\beta$ secretion, respectively, was accompanied by inhibition of corresponding mRNA levels (fig 6). IL-10 upregulated secretion of IL-1ra in a dose dependent manner (table 3). Neither IBD nor normal control PMN were secreting any detectable IL-10 (data not shown).

\section{Discussion}

It has been suggested that both IL-1 $\beta$ and TNF- $\alpha$ may be important mediators involved in the initiation and perpetuation of intestinal inflammation in IBD. This study demonstrates 
that enhanced levels of both cytokines are released by purified peripheral polymorphonuclear neutrophils from patients with intestinal inflammation. Our main understanding has been that PMN will enter inflamed sites in the intestine in great numbers, ${ }^{1-45152}$ unload mostly non-specific molecules including superoxide anions, lipid mediators and proteases, and then transmigrate through the bowel wall into the lumen. ${ }^{38}$ This view of the neutrophil as a short lived cell which does not partake in specific immunoregulation was modified by recent studies which showed that: (1) normal PMN are capable of a stimulus dependent release of a host of cytokines in vitro, ${ }^{29-31}{ }^{38}(2)$ corresponding cytokine mRNAs could be induced in PMN, ${ }^{303138}$ and (3) activation of PMN prolongs their life span by preventing apoptosis (RD Lohmann and S Schreiber, unpublished data).

This study now shows that PMN carry the capacity to release increased amounts of IL- $1 \beta$ and $\mathrm{TNF}-\alpha$ in vitro in active inflammatory bowel disease and infectious colitis. On stimulation with lipopolysaccharide, pro- inflammatory cytokine secretion is maximised in PMN from patients with intestinal inflammation. Increased amounts of pro-inflammatory cytokines which have been found in both the mucosa $a^{9-18}$ and the faeces ${ }^{20}$ of patients with IBD may therefore be produced to a considerable part by PMN. Increased secretion of proinflammatory cytokines does not appear to be specific for IBD because PMN from patients with infectious colitis also showed increased release of IL- $1 \beta$ and TNF- $\alpha$.

Interleukin 1 receptor antagonist can competitively block IL-1 $\beta$ from binding to its receptor. Secretion of IL-1ra as an antiinflammatory molecule is therefore regarded as an important negative feedback mechanism to limit the potential pro-inflammatory effects of IL-1 $\beta .{ }^{193}$ We did not observe any statistically significant differences in molar ratios of IL-1 ra to IL-1 $\beta$ between PMN from normal controls and patients with IBD. Deficient secretion of IL-1 ra does not therefore appear to play a pivotal role in PMN mediated immunoregulation.

The immunological activation of neutrophils can be divided into "priming" and "activation". 8212526 We hypothesise that our in vitro findings show an increased level of priming of circulating neutrophils leads to enhanced secretion of pro-inflammatory cytokines. Only upon activation by a secondary stimulus (lipopolysaccharide) may PMN from patients with intestinal inflammation secrete increased amounts of pro-inflammatory cytokines into the mucosa. As neutrophils are excreted with the faeces in patients with IBD, these cells may contribute to the increased levels of TNF- $\alpha$ which were found in the stools of children with IBD or infective diarrhoea. ${ }^{20}$ However, little is known about the in vivo penetration of lipopolysaccharide as a stimulus for cytokine release into the inflamed mucosa. Further studies which address the in vivo role of PMN in the inflamed mucosa are therefore necessary.

The detection of pro-inflammatory cytokine mRNA in PMN from both normal controls and patients with IBD indicate that cytokine production may be tightly regulated in PMN. Interleukin 10 is a powerful contrainflammatory molecule inducing downregulation of macrophage as well as of $\mathrm{T}$ (h1) lymphocyte activation. ${ }^{32-37}$ Moreover, recent studies indicate a potential role for IL-10 as an anti-inflammatory therapeutic agent in inflammatory bowel disease, which inhibits proinflammatory cytokine secretion from mononuclear phagocytes in vitro and in vivo. ${ }^{37}{ }^{39}$ Our observations indicate that IL-10 has the capacity to inhibit both pro-inflammatory cytokine mRNA levels and secretion in polymorphonuclear neutrophils from patients with IBD and induces secretion of IL-1 ra.

The detection of cytokine mRNA in PMN already indicated that the inflammatory activation of these cells may be restricted by complex transcriptional controls. Activation of NF- $\kappa \mathrm{B}$ may be a pivotal event in pro-inflammatory signal transduction and transcriptional regulation. ${ }^{55} 5$ Future studies will therefore address the role of cytokine transcription factors in PMN and other inflammatory cells in patients with IBD.

We have shown that neutrophils from patients with intestinal inflammation secrete high levels of TNF- $\alpha$ and IL- $1 \beta$ in comparison with normal control PMN after stimulation with lipopolysaccharide. Interleukin 10 is a powerful inhibitor of pro-inflammatory cytokine secretion and transcription by PMN in both patients with IBD and normal controls. As activation prolongs the short life span of $\mathrm{PMN},{ }^{56}$ we conclude that neutrophils may be important contributors to the initiation and perpetuation of mucosal inflammation and deserve further attention as competent immunoregulatory cells.

This work was supported by a grant from the Deutsche Forschungsgemeinschaft (SCH 512/1-2 to SS), by a European Training and Mobility of Research Network Grant (ERB-4061PL-97-0389), by a stipend from the German Crohn's and Colitis Foundation (DCCV) to SN, and by development grants from Genzyme GmbH and MFG.

1 Saverymuttu SH, Peters AM, Lavender JP, et al. In vivo assessment of granulocyte migration to diseased bowel in Crohn's disease. Gut 1985;26:378-83.

2 Saverymuttu SH, Chadwick VS, Hodgson HJ. Granulocyte migration in ulcerative colitis. Eur F Clin Invest 1985;15:608.

3 Saverymuttu SH, Peters AM, Lavender JP, et al. Quantitative fecal indium 111-labeled leucocyte excretion in the assessment of disease activity in Crohn's disease. Gastroenterology 1983;85:1333-9.

4 Schoelmerich J, Schmidt E, Schumichen C, et al. Scintigraphic assessment of bowel involvement and disease activity in Crohn's disease using technetium $99 \mathrm{~m}$ hexamethyl propylene amine oxine as leukocyte label. Gastroenterology propylene amine oxin

5 Malizia G, Calabrese A, Cottone M, et al. Expression of leukocyte adhesion molecules by mucosal mononuclear phagocytes in inflammatory bowel disease. Gastroenterology 1991;100:150-9.

6 Koizumi M, King N, Lobb R, et al. Expression of vascular adhesion molecules in inflammatory bowel disease. Gastroenterology 1992;103:840-7.

7 Albelda SM, Smith CW, Ward PA. Adhesion molecules and inflammatory injury. FASEB f 1994;8:504-12.

8 Guthrie LA, McPhail LC, Henson PM, et al. Priming of neutrophils for enhanced release of oxygen metabolites by bacterial lipopolysaccharide, evidence for increased activity of the superoxide-producing enzyme. 7 Exp Med 1984;160: 1656-71.

9 Schreiber S, Raedler A, Stenson WF, et al. The immunology of inflammatory bowel disease. Gastroenterol Clin North Am 1992;21:451-502.

10 Mahida YR, Wu K, Jewell DP. Enhanced production of interleukin $1-\beta$ by mononuclear cells isolated from mucosa 
with active ulcerative colitis or Crohn's disease. Gut 1989; 30:835-8.

11 Ligumsky M, Simon PL, Karmeli F, et al. Role of interleukin 1 in inflammatory bowel disease - enhanced production during active disease. Gut 1990;31:686-9.

12 MacDonald TT, Hutchings P, Choy MY, et al. Tumour necrosis factor-alpha and interferon-gamma production measured at the single cell level in normal and inflamed human intestine. Clin Exp Immunol 1990;81:301-5.

13 Brynskov J, Tvede N, Andersen CB, et al. Increased concentrations of interleukin $1 \beta$, interleukin 2 , and soluble interleukin-2 receptors in endoscopic mucosal biopsy specimens with active inflammatory bowel disease. Gut 1992;33:55-8.

14 Pullman WE, Elsbury S, Masanobu K, et al. Enhanced mucosal cytokine production in inflammatory bowel disease. Gastroenterology 1992;102:529-37.

15 Schreiber S, Raedler A, Conn AF, et al. Increased release of soluble interleukin-2 receptor by colonic lamina propria mononuclear cells in inflammatory bowel disease. Gut 1992;32:236-9.

16 Stevens C, Walz G, Singaram C, et al. Tumor necrosis factor- $\alpha$, interleukin- $1 \beta$ and interleukin 6 expression in inflammatory bowel disease. Dig Dis Sci 1992;37:818-26.

17 Isaacs KL, Sartor RB, Haskill S. Cytokine messenger RNA profiles in inflammatory bowel disease mucosa detected by polymerase chain reaction amplification. Gastroenterology 1992;103:1587-95.

18 Reinecker H-C, Steffen M, Witthoeft T, et al. Enhanced secretion of tumor necrosis factor-alpha, IL-6, and IL-1 beta by isolated lamina propria mononuclear cells from patients with ulcerative colitis and Crohn's disease. Clin Exp Immunol 1993;94:174-81.

19 Dinarello CA, Wolff SM. The role of interleukin 1 in disease. $N$ Engl f Med 1993;328:106-13.

20 Nicholls S, Stephens S, Braegger CP, et al. Cytokines in stools of children with inflammatory bowel disease or infective diarrhoea. F Clin Pathol 1993;46:757-60.

21 Grisham MB, Granger DN. Neutrophil mediated mucosal injury. Role of reactive oxygen metabolites. Dig Dis $\mathrm{Sci}$ 1988:33:6S-15S

22 Faden H, Rossi TM. Chemiluminescent response of neutrophils from patients with inflammatory bowel disease. Dig Dis Sci 1985;30:139-42.

23 Anton PA, Targan SR, Shanahan F. Increased neutrophil receptors for and response to the pro-inflammatory bacterial peptide formyl-methionyl-leucyl-phenylalanine in Crohn's disease. Gastroenterology 1989;97:20-8.

24 Kelleher D, Feighery C, Weir DG. Chemiluminescence by polymorphonuclear leucocyte subpopulations in chronic inflammatory bowel disease. Influence of the cell separation procedure. Digestion 1990;45:158-65.

25 Baldassano RN, Schreiber S, Johnston RB, et al. Monocytes of patients with Crohn's disease are primed for accentuated release of toxic oxygen metabolites: possible role for endotoxin. Gastroenterology 1993;105:60-6.

26 Griga T, Tromm A, Schwegler U, et al. Enhanced superoxide anion release of normal neutrophil granulocytes primed with sera of patients with inactive inflammatory bowel diswith sera of patients with inactive in

27 Andus T, Gross V, Caesar I, et al. PMN-elastase in assessment of patients with inflammatory bowel disease. assessment of patients with in
Dig Dis Sci 1993;38:1638-44.

28 Adeyemi EO, Hodgson HJ. Faecal elastase reflects disease activity in active ulcerative colitis. Scand $\mathcal{f}$ Gastroentero 1992;27:139-42.

29 Bazzoni F, Cassatella MA, Laudanna C, et al. Phagocytosis of opsonized yeast induces tumor necrosis factor alpha mRNA accumulation and protein release by human polymorphonuclear leukocytes. F Leukocyte Biol 1991;50: 223-8.

30 Cassatella MA, Meda L, Bonora S, et al. Interleukin 10 (IL10) inhibits the release of pro-inflammatory cytokines from human polymorphonuclear leukocytes. Evidence for an autocrine role of tumor necrosis factor and IL- $1 \beta$ in mediating the production of IL- 8 triggered by lipopolysacchaating the production of IL-8 trigge
ride. $\mathcal{F}$ Exp Med 1993;1

31 Cassatella MA. The production of cytokines by polymorphonuclear neutrophils. Immunol Today 1995;16:21-6.

32 Vieira P, de Waal-Malefyt R, Dang M, et al. Isolation and expression of human cytokine synthesis inhibitory factor
(CSIF/IL-10) c-DNA clones: homology to Epstein-Barr irus open reading frame BCRFI. Proc Natl Acad Sci USA 1991;88:1172-7.

33 de Waal Malefyt R, Yssel H, Roncarolo M-G, et al. Interleukin 10. Curr Opin Immunol 1992;4:314-22.

34 Fiorentino DF, Zlotnik A, Mosmann TR, et al. IL-10 inhibts cytokine production by activated macrophages. F Immunol 1991;147:3815-22.

35 Ralph P, Nakoinz I, Sampson-Johannes A, et al. IL-10, T lymphocyte inhibitor of human blood cell production of ILmphocyte inhibitor of human blood cell production of 14

36 de Waal Malefyt R, Abrams J, Bennett B, et al. Interleukin 10 (IL-10) inhibits cytokine synthesis by human monocytes: an autoregulatory role of IL-10 produced by monocytes. F Exp Med 1991;174:1209-20.

37 Schreiber S, Heinig T, Thiele HG, et al. Immunoregulatory role of interleukin 10 in inflammatory bowel disease in vitro and in vivo. Gastroenterology 1992;108:1434-44.

38 Cassatella MA, Meda L, Gasperini S, et al. Interleukin 10 (IL-10) upregulates IL-1 receptor antagonist production from lipopolysaccharide-stimulated human polymorphonuclear leucocytes by delaying mRNA degradation. $\mathcal{F}$ Exp Med 1994:179:1695-9.

39 van Deventer SJH, Elson CO, Fedorak RN for the Crohn's disease study group. Multiple doses of intravenous nterleukin 10 in steroid-refractory Crohn's disease. Gastroenterology 1997;113:383-90.

40 Best WR, Becktel JM, Singleton JW, et al. Development of a Crohn's disease activity index. National Cooperative Crohn's Disease Study. Gastroenterology 1976;70:439-44.

41 Rachmilewitz D. Coated mesalazine (5-aminosalicylic acid) versus sulphasalazine in the treatment of active ulcerative colitis: a randomized trial. BMF 1989;298:82-6.

42 Gasperini S, Donini M, Dusi S, et al. Interleukin-10 decreases tyrosine phosphorylation of discrete lipopolysaccharide-induced phosphorylation in human granulocytes. Biochem Biophys Res Commun 1995;209:8794.

43 Metcalf JA, Gallini JI, Nauseef WN, et al. Laboratory manual of neutrophil function. New York: Raven Press, 1989:109.

44 Yam LT, Li CY, Crosby WH. Cytochemical identification of monocytes and granulocytes. Am f Clin Pathol 1971;55: 283-90.

45 Bienvenu J, Coulon L, Doche C, et al. Analytical performance of commercial ELISA-kits for IL-2, IL-6 and TNF- $\alpha$. A WHO study. Eur Cytokine Netw 1993;4:447-51.

46 Chromczynski P, Sacchi N. Single-step method of RNA isolation by acid guanidium thiocyanate-phenol-chloroform extraction. Anal Biochem 1987;162:156-9.

47 Wang AM, Doyle MV, Mark DF. Quantitation of mRNA by the polymerase chain reaction. Proc Natl Acad Sci USA 1989;86:9717-21.

48 Lilliefors HW. On the Kolmogorov-Smirnov test for normality with mean and variance unknown. I Am Stat Assoc 1967;64:399-402.

49 Sachs L. Angewandte statistik. 7th edn. Heidelberg, New York, Tokyo: Springer, 1992.

50 Mann HB, Whitney DR. On a test of whether one of two random variables is stochastically larger than the other. Ann Math Statistics 1947;18:50-60.

51 Raab Y, Gerdin B, Ahlstedt S, et al. Neutrophil mucosal involvement is accompanied by enhanced local production of interleukin-8 in ulcerative colitis. Gut 1993;34:1203-6.

52 Monajemi H, Meenan J, Lamping R, et al. Inflammatory bowel disease is associated with increased mucosal levels of bactericidal/permeability-increasing protein. Gastroenterology 1996;110:733-9.

53 Dinarello CA. Interleukin-1 and interleukin-1 antagonism. Blood 1991;77:1627-52.

54 Lenardo MJ, Baltimore D. NF-kappa B: a pleiotropic mediator of inducible and tissue-specific gene control. Cell 1989;58:227-9.

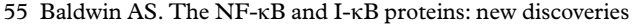
and insights. Annu Rev Immunol 1996;14:649-81.

56 Colotta F, Re F, Polentarutti N, et al. Modulation of granulocyte survival and programmed cell death by cytokines and bacterial products. Blood 1992;80:2012-20. 